\title{
ÁMBITO DE APLICACIÓN PERSONAL DEL REGLAMENTO 2016/1104 SOBRE RÉGIMEN PATRIMONIAL DE LA PAREJA REGISTRADA ${ }^{1}$
}

\section{Mercedes Soto Moya}

Profesora titular de derecho internacional privado

Universidad de Granada

E-mail: mercedessoto1978@gmail.com

\begin{abstract}
RESUMEN: La entrada en vigor, en enero de 2019, del Reglamento (UE) 2016/1104, supuso una verdadera revolución en el ámbito del DIPr. No obstante, la diversidad de las reglas nacionales de Derecho internacional privado aplicables a los derechos de propiedad de las parejas internacionales unida a la diferente o nula regulación de la institución "pareja registrada" que realizan los Estados miembros, ha evidenciado déficits en la norma. Nos centramos en este trabajo en analizar: cuál ha de ser el país de registro, su naturaleza, o si están incluidas o no en su ámbito de aplicación las parejas registradas del mismo sexo.
\end{abstract}

Palabras clave: Unión Europea; parejas internacionales; Reglamento (UE) 2016/1104; régimen patrimonial de las uniones registradas; cooperación reforzada; ámbito de aplicación personal.

\begin{abstract}
The entry into force on January 29, 2019 of the Council Regulation (EU) 2016/1104, was a true revolution in the field of EU PIL. However, the diversity of the national rules of private international law applicable to the property rights of international couples, together with the different or null regulation of the "registered partner" institution carried out by the Member States, have evidenced some deficits of the norm. We focus in this work on analyzing: which country of registration should be, their nature, or if the same sex registered partners are included in its personal scope.
\end{abstract}

Keywords: European Union; International couples; Council Regulation (EU) 2016/1104; Property consequences of registered partnerships; Enhanced cooperation, Personal scope.

1 Este artículo se enmarca en el Proyecto de $\mathrm{I}+\mathrm{D}+\mathrm{i}$ "Retos de la regulación jurídico-patrimonial del matrimonio y de otras realidades (uniones de hecho) en los planos supraestatal y estatal (REJURPAT)”, código PID2019106496RB-I00, en el marco de los Programas Estatales de Generación de Conocimiento y Fortalecimiento Científico y Tecnológico del Sistema de I+D+i. IP: D. Andrés Rodríguez Benot. 
SUMARIO: I. INTRODUCCIÓN; II. PAÍS DE REGISTRO; III. INDEFINICIÓN CON RESPECTO A LAS PAREJAS REGISTRADAS DEL MISMO SEXO; IV. NATURALEZA DEL REGISTRO: ESPECIAL REFERENCIA A LA ATOMIZACIÓN DEL SISTEMA ESPAÑOL; V. CONCLUSIONES; VI. BIBLIOGRAFÍA.

\section{INTRODUCCIÓN}

La eliminación de los obstáculos a la libre circulación de personas ha sido, y sigue siendo, el objetivo recurrente de todos y cada uno de los Reglamentos UE en materia de Derecho internacional privado que han entrado en vigor en las últimas décadas y el Reglamento (UE) 2016/1104, no se queda a la zaga². En su caso concretándolo en la resolución de los problemas a los que se enfrentan las parejas en la administración de su patrimonio. Se pretende conseguir que los miembros de una unión registrada puedan organizar sus relaciones patrimoniales entre sí y con terceros durante su vida en pareja y al liquidar su patrimonio, así como una mayor previsibilidad y seguridad jurídica ${ }^{3}$. La norma tiene entre sus objetivos facilitar a las parejas la resolución de cuestiones relacionadas con la propiedad en caso de que se trasladen a otro Estado miembro de la UE o de que, siendo de países diferentes, tengan propiedades en el extranjero.

No obstante, la consecución de dicho objetivo no es sencilla. Las dificultades en este ámbito no solo se suscitan por la diversidad de las reglas nacionales de Derecho internacional privado aplicables a los derechos de propiedad de las parejas internacionales, sino por la diferente o nula regulación (en algunos casos) de la institución "pareja registrada" que realizan los Estados miembros. Este, precisamente, ha sido el motivo fundamental por el que se ha tenido que acudir para la elaboraciónd el Reglamento 2016/1104, a la vía de la cooperación reforzada, consolidando la idea de la Europa a la carta o a múltiples velocida$\mathrm{des}^{4}$. Las diferencias irreconciliables entre los países hacían imposible un acuerdo en una materia que forma parte del Derecho de familia lato sensu $u^{5}$. Hay que recordar que la UE no tiene competencia exclusiva en este ámbito y no puede imponer a los Estados miembros normas que les obliguen a transformar sus legislaciones internas. A pesar de que se intentó hasta el último momento la adhesión de todos los países UE, al final no se consiguió, ni siquiera con la inclusión del considerando 17, que no deja lugar a dudas: "el contenido real del concepto de unión registrada debe seguir regulándose en el Derecho nacional de los Estados miembros. Ninguna de las disposiciones del presente Reglamento deberá

2 Reglamento (UE) 2016/1104 de Consejo de 24 de junio por el que se establece una cooperación reforzada en el ámbito de la competencia, la ley aplicable, el reconocimiento y ejecución de resoluciones en materia de regímenes patrimoniales de las uniones registradas.

3 Objetivo compartido con el paralelo Reglamento (UE) 2016/1103 relativo a la competencia, ley aplicable, reconocimiento y ejecución de resoluciones en materia de regímenes económicos matrimoniales.

4 Otras expresiones utilizadas para describir este fenómeno han sido, por ejemplo, "geometría variable", "integración diferenciada" o "flexibilidad en la integración”. Vid., por todos, ANDRÉS SÁENZ DE SANTA MARÍA, P., "El tiempo de las cooperaciones reforzadas y los acuerdos inter se en la Unión Europea: ¿todos los instrumentos llevan a la integración?", La Ley: Unión Europea, núm. 10, 2013, pp. 5-28.

5 De ahí que la base jurídica del Reglamento sea el art. 81.3 TFUE. Es el Consejo, por tanto, previa consulta al Parlamento Europeo, el que tiene competencia para adoptar medidas relativas al Derecho de familia con repercusión transfronteriza. Vid. PINTENS, W., "Union européenne et l'émergence d'un droit international de la famille - L'exemple des régimes matrimoniaux et des effets patrimoniaux des partenariats enregistrés", Herausforderungen an Staat und Verfassung. Liber Amicorum für Torsten Stein zum 70. Geburtstag, Nomos, 2015, pp.806-822. 
obligar a los Estados miembros cuyo ordenamiento jurídico no contemple la institución

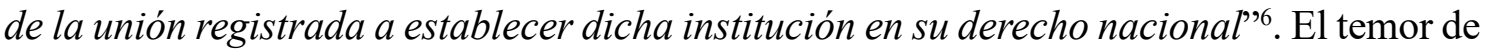
algunos países a que la adopción del Reglamento pudiera conllevar una apertura paulatina a la regulación de las parejas del mismo sexo desincentivó su adhesión?

Nuestro propósito en este trabajo es analizar el ámbito de aplicación personal del Reglamento (UE) 2016/1104 y determinar a qué parejas resultará de aplicación. Es ésta una cuestión que siempre ha de establecerse de manera previa. Antes de concretar qué autoridad resultará competente, o qué ley se aplicará a la determinación del régimen económico de la pareja, el operador jurídico habrá que establecer si se empleará el Reglamento (UE) 2016/1104. Para ello, la propia norma UE, establece en su art. 3.1 a) que se aplicará a las parejas registradas, a las que define como: "el régimen de vida en común de dos personas regulado por ley, cuyo registro es obligatorio conforme a dicha ley y que cumple las formalidades jurídicas exigidas por dicha ley para su creación". Adicionalmente, el considerando 16 circunscribe la aplicación del Reglamento (UE) a las "parejas cuya unión se halle institucionalmente sancionada mediante su registro ante una autoridad pública".

Por tanto, parece claro que cualquier pareja que no se encuentre registrada no entrará a formar parte del ámbito de aplicación personal de este Reglamento (UE), descartando por completo las parejas de hecho o, quizás, siendo más precisos, las parejas no registradas $^{8}$. El motivo, según señala la propia norma es que su carácter oficial permite tener en cuenta su especificidad y proceder a su regulación en el Derecho de la Unión. Hay autores que interpretan la definición del art. 3.1 a) incluso de una manera más flexible, entendiendo que "lo importante es que se trate de una unión regulada con un régimen patrimonial o de bienes más o menos unitaria y que esté registrada o haya sido formalizada, cara a la sociedad, ante la autoridad pública".

6 Tal como señala RODRÍGUEZ BENOT, A., ("Los efectos patrimoniales de los matrimonios y de las uniones registradas en la Unión Europea”, Cuadernos de derecho transnacional, Vol. 11, núm. 1, 2019, pp.8-50, p.26), "en buena medida, la decisión de Hungría y de Polonia en la sesión del Consejo JAI de diciembre de 2015 de no participar en este instrumento -y tampoco en el paralelo 2016/1103- estuvo fundada en la idea de no admitir -siquiera indirectamente las consecuencias de los matrimonios o de las uniones registradas entre personas del mismo sexo válidas en otros sistemas; ello derivó en la necesidad de recurrir a la cooperación reforzada para la aprobación de ambos Reglamentos (artículo 70 y considerandos 11, 12, 13 y 70 ”.

7 QUINZÁ REDONDO, P., "Unificación -fragmentada- del Derecho internacional privado de la Unión Europea en materia de régimen económico matrimonial: el Reglamento 2016/1103", Revista General de Derecho Europeo, núm. 41, 2017, pp. 180-222, p.185.

8 Al regular la convivencia de las parejas no casadas, los legisladores nacionales han optado entre dos modelos legislativos básicos: el modelo fáctico (parejas de hecho) y el modelo formal (parejas registradas). Por lo que respecta al primero de ellos, el punto de partida es una situación de convivencia estable de la que se hacen depender ciertos efectos jurídicos, que se ponen especialmente de manifiesto en caso de ruptura. Estos efectos han de ser, no obstante, mínimos, puesto que, al atribuirse al margen de la voluntad de las partes, se podría conculcar la vertiente negativa del derecho a contraer matrimonio, esto es, el derecho a no casarse. El otro modelo de regulación es el denominado modelo formal, que se basa en una declaración de voluntad de las partes, de la que se hacen depender unos efectos jurídicos más o menos análogos al matrimonio. GONZÁLEZ BEILFUSS, C., Parejas de hecho y matrimonios del mismo sexo en la UE, Barcelona, Marcial Pons, 2004; Hay autores que distinguen tres tipos de uniones registradas, uniones de pareja legales, es decir, las reguladas por ley con un estatuto unitario y las uniones libre o de hecho. Vid. QUIÑONES ESCÁMEZ, A, "Nuevos tipos de uniones y nueva regulación de sus efectos", Persona y familia en el nuevo modelo español de Derecho internacional privado, Tirant lo Blanch, Valencia, 2017, pp.169-189, p. 183.

9 QUIÑONES ESCÁMEZ, A., "Problemas generales de derecho internacional privado en los nuevos reglamentos europeos en materia de regímenes matrimoniales y efectos patrimoniales de las uniones registradas", Cursos de derecho internacional y relaciones internacionales de Vitoria-Gasteiz, ${ }^{\circ}$ 1, 2018, pp. 245 -335, p.281. 
No obstante, esta afirmación no aclara otros muchos interrogantes que se suscitan, como cuál ha de ser el país de registro, la naturaleza del mismo, o si están incluidas o no en su ámbito de aplicación las parejas registradas del mismo sexo. Y éstas son las cuestiones en las que centraremos el análisis en las próximas páginas ${ }^{10}$.

\section{PAÍS DE REGISTRO}

Como se acaba de indicar supra, la condición sine qua non que establece el art. 3.1 a) para la aplicación del Reglamento (UE) 2016/1104, es la del registro de la unión. Lo que no aclara ni en los considerandos, ni en el resto de su articulado, es si la pareja ha tenido que registrase en de uno de los Estados vinculados por el Reglamento (recordemos que es una norma de cooperación reforzada de la que no forman parte todos los países de la $\mathrm{UE}^{11}$ ), en un país de la UE o en cualquier otro Estado del mundo.

La falta de concreción de la norma no ayuda a decantarse por ninguna de las opciones. En una primera aproximación parecería que su aplicación quedaría circunscrita a las parejas registradas en un Estado que forme parte del Reglamento (UE) 2016/1104. Esta solución, sin embargo, nos parece muy restrictiva y poco acorde con el espíritu y finalidad de la norma UE. Hay que poner de relieve, en primer lugar, que el artículo 3.1 del Reglamento preceptúa que la unión registrada es un régimen de vida en común de dos personas regulado por ley, cuyo registro es obligatorio conforme a dicha ley", pero no añade que tenga que ser la ley de un Estado miembro. El segundo argumento a favor de la extensión es, que el paralelo Reglamento (UE) 2016/1103 sobre régimen económico del matrimonio, no circunscribe su aplicación a matrimonios celebrados en un Estado parte, sino a los celebrados en cualquier país del mundo. Ambos Reglamentos fueron elaborados a la par y entraron en vigor el mismo día ${ }^{12}$. Los dos instrumentos jurídicos estructuran su contenido de forma idéntica, abordando, la competencia judicial, la ley aplicable, el reconocimiento de resoluciones y documentos, la oponibilidad frente a terceros, y concluyen con las disposiciones generales y finales. De hecho, en un principio se intentó que ambas materias se incluyeran en una sola norma, aunque finalmente se reveló como algo imposible y se procedió al

10 Somos conscientes de la multiplicidad de cuestiones que plantea la aplicación del Reglamento 1104/2016 y que no analizaremos por no ser el objeto de este trabajo. Entre ellas, por ejemplo, la delimitación de la función de los notarios y su consideración de autoridades judiciales, la aceptación del documento público extranjero al cobijo del Reglamento 2016/1104, o qué se entiende por "relaciones patrimoniales" a efectos de aplicación del Reglamento. Baste recordar en este sentido cómo los Estados del common law ignoran esta categoría y prefieren atender a otros conceptos como los alimentos o pensiones a la hora de establecer las consecuencias de una disolución de la pareja registrada. Sin olvidar algunas cuestiones más concretas, pero muy habituales, como las complicaciones que se suscitarán en torno a la inscripción en el Registro de la Propiedad de una escritura de compraventa bajo régimen patrimonial de la pareja extranjero, si las partes no han elegido la ley aplicable al respecto. Vid. SOTO MOYA, M., "El Reglamento 1104/2016 sobre régimen patrimonial de las parejas registradas: algunas cuestiones controvertidas de su puesta en funcionamiento en el sistema español de DIPr.”, REEI, núm. 35, diciembre 2018.

11 En el momento de elaboración de este trabajo los Estados cuyas autoridades los aplican son Alemania, Austria, Bélgica, Bulgaria, Croacia, Chipre, Eslovenia, España, Finlandia, Francia, Grecia, Italia, Luxemburgo, Malta, Países Bajos, Portugal, la República Checa y Suecia.

12 Los Reglamentos entraron en vigor el 28 de julio de 2016, a los veinte días de su publicación en el Diario Oficial de la Unión Europea (art. 70 de ambos Reglamentos). 
desdoblamiento ${ }^{13}$. Por tanto, no parece descabellado pensar que al igual que la aplicación del Reglamento 2016/1103 se extiende a los matrimonios celebrados en cualquier país del mundo, la del Reglamento 2016/1104 también lo haga con las parejas registradas.

En tercer lugar, es necesario recordar el carácter universal de la ley aplicable designada por las normas del Reglamento (art. 20). No resultaría coherente que la autoridad competente del Estado en cuestión pudiese aplicar la ley de cualquier país del mundo para sustanciar un problema relativo al régimen patrimonial de la pareja, y restringir la aplicación del Reglamento a aquellas parejas registradas en un Estado miembro.

Por último, hay que poner de relieve que hay otras normas de la UE que sí han limitado específicamente su aplicación a aquellas parejas registradas en un Estado miembro. Así, por ejemplo, la Directiva 2004/38 del Parlamento Europeo y del Consejo relativa al derecho de los ciudadanos de la Unión y de los miembros de sus familias a circular y residir libremente en el territorio de los Estados miembros ${ }^{14}$. En su artículo 2.2 b) permite la libre circulación de personas con carácter derivado específicamente a "la pareja con la que el ciudadano de la Unión ha celebrado una unión registrada, con arreglo a la legislación de un Estado miembro", locución que no se ha incluido en el Reglamento (UE) 2016/1104 ${ }^{15}$.

\section{INDEFINICIÓN CON RESPECTO A LAS PAREJAS REGISTRADAS DEL MISMO SEXO}

La inclusión o no de las parejas registradas del mismo sexo en el ámbito de aplicación del Reglamento (UE) 2016/1104, ha sido el gran caballo de batalla de las negociaciones y una de las razones fundamentales de que no todos los Estados de la UE hayan aceptado formar parte de él. Y esto a pesar de los ímprobos esfuerzos por despejar cualquier duda acerca de la total libertad de los países para regular "el contenido real del concepto de unión registrada” (vid. Supra, Considerando 17). Renunciando, incluso, a la creación de un contenido homogéneo que sería imprescindible para dotar de una mínima seguridad jurídica a la norma. No debe sorprender, no obstante, este modus operandi, ya que el legislador UE no suele elaborar conceptos autónomos en el ámbito del Derecho de familia, sino que en la mayoría de las ocasiones traslada este cometido a los ordenamientos jurídicos de los

13 El germen de estos dos instrumentos jurídicos se encuentra en el "Plan de Acción del Consejo y la Comisión sobre la mejor manera de aplicar las disposiciones del Tratado de Ámsterdam relativas a la creación de un espacio de libertad, seguridad y justicia" (DOCE C 19, de 25 de enero de 1999). Si bien en aquel momento nada se indicaba sobre las uniones more uxorio, muy poco después se incorporó a la agenda, a raiz del "Proyecto de medidas para la aplicación del principio de reconocimiento mutuo de las resoluciones judiciales en materia civil y mercantil" (DO C 12 de 15.1.2001), que preveía la elaboración de un instrumento sobre la "competencia judicial, el reconocimiento y la ejecución de las resoluciones en materia de los regímenes matrimoniales y las consecuencias patrimoniales de la separación de parejas no casadas". El Programa de Estocolmo, adoptado por el Consejo Europeo el 11 de diciembre de 2009, declaró que el reconocimiento mutuo debe extenderse a los regímenes matrimoniales y a las consecuencias patrimoniales de la separación de la pareja. Y, en el "Informe 2010 sobre la ciudadanía de la Unión: la eliminación de los obstáculos a los derechos de los ciudadanos de la UE” (COM (2010) 603), adoptado el 27 de octubre de 2010, la Comisión señaló que la incertidumbre respecto de los derechos de propiedad de las parejas internacionales era uno de los principales obstáculos a los que se seguían enfrentando los ciudadanos de la UE en su vida cotidiana cuando ejercitan los derechos que les reconoce la UE más allá de las fronteras nacionales. Finalmente se optó por desdoblar la regulación para los matrimonios y las parejas registradas.

14 DOCE L 158, de 30 de abril de 2004. Corrección de errores, DOCE L 229/35, de 29 de junio de 2004.

15 Vid. SOTO MOYA, M., "El Reglamento 1104/2016 sobre régimen patrimonial de las parejas registradas...”, loc. cit. 
Estados miembros. Esta remisión — presente también en los Reglamentos 2201/2003 ${ }^{16}$, $4 / 2009^{17}, 1259 / 2010^{18}$ y 2016/1103 — es la razón de que sea cada Estado el que interprete, a tenor de sus propios criterios, los conceptos introducidos en las normas de la UE. Así, se inserta una inevitable nota heterogénea en el ámbito material del Derecho de la UE ${ }^{19}$.

La neutralidad del Reglamento (UE) con respecto a la inclusión o no de las parejas del mismo sexo conlleva que en todos los supuestos que se planteen en relación con su régimen económico será imprescindible resolver la cuestión previa de si se incluyen o no en su ámbito de aplicación, asunto que será resuelto de manera distinta según el Estado miembro de la UE donde se produzca la disolución de la unión, el que esté conociendo de la sucesión de uno de los miembros de esa pareja, donde se deseen hacer capitulaciones....etc.

La indefinición de la norma ocasiona problemas también en el ámbito de las relaciones de compatibilidad entre el Reglamento (UE) 1103/2016 y el 1104/2016. Si imagináramos dichas normas como circunferencias secantes, las parejas, tanto matrimoniales como registradas del mismo sexo, estarían en la zona de convergencia entre ambas. El motivo fundamental es que, así como el matrimonio entre personas de distinto sexo es una institución consolidada que se ha mantenido intacta e incuestionable a través del tiempo, las uniones entre personas de distinto sexo podrían calificarse como una "institución líquida" (acuñando, la categoría central sobre la que BAUMAN construyó su edificio conceptual) ${ }^{20}$. Las viejas instituciones de la modernidad (sólidas) se van diluyendo y son sustituidas por estados flexibles. En el ámbito de las uniones del mismo sexo cada país o incluso región (en el caso de España, por ejemplo) las ha regulado de una manera diferente. Así, hay países que no contemplan la posibilidad de que las parejas del mismo sexo se registren, solo pueden contraer matrimonio (como en Finlandia o Suecia) ${ }^{21}$. ¿Se aplicará en estos países el Reglamento (UE) 1104/2016 a las parejas del mismo sexo registradas en otro Estado? Es decir, ¿considerarán la pareja registrada del mismo sexo una institución desconocida y la asimilarán al matrimonio o por el contrario entenderán que sí les resulta de aplicación la norma UE? Por otro lado, hay otros Estados parte en los que las parejas del mismo sexo no tienen acceso al matrimonio, solo pueden constituir una pareja

16 DOCE L 338, de 23 de diciembre de 2003.

17 Reglamento 4/2009, del Consejo, de 18 de diciembre de 2008, relativo a la competencia, la ley aplicable, el reconocimiento y la ejecución de las resoluciones y la cooperación en materia de obligaciones de alimentos (Bruselas III)

18 Reglamento (UE) núm. 1259/2010 del Consejo de 20 de diciembre de 2010 por el que se establece una cooperación reforzada en el ámbito de la ley aplicable al divorcio y a la separación judicial, DOUE, de 29 de diciembre de 2010.

$19 \mathrm{Y}$ esto a pesar de que el instrumento jurídico elegido ha sido el Reglamento, lo que debería evitar la disparidad en los ordenamientos jurídicos de los diferentes Estados miembros, que no pueden introducir variantes en sus respectivas legislaciones. No obstante, la unificación solo ha llegado a los aspectos procesales. Como expresa CAMPUZANO DÍAZ, B. ("La política legislativa de la UE en materia de DIPr. de familia. Una valoración de conjunto", Cuadernos de Derecho Transnacional, 2013, Vol. 5, No 2, pp. 234-264, pp. 238) "se está permitiendo la diversidad en el marco de la uniformidad".

20 BAUMAN, Z, Liquid Modernity, Cambridge, Polity Press, 2000.

21 La Ley de matrimonio del mismo sexo sueca que entró en vigor a finales de abril de 2009, derogó la Ley de uniones registradas que continúa, no obstante, produciendo efectos jurídicos respecto de las parejas que registraron su unión antes de finales de abril de 2009 y no han convertido su unión en matrimonio desde entonces . En Finlandia, el matrimonio del mismo sexo es legal desde marzo de 2017, de acuerdo con la ley aprobada por el parlamento el 12 de diciembre de 2014, por lo que también se ha derogado la ley de parejas registradas (Lagom ändring av äktenskapslagen, 156/2015. Disponible en http://www.finlex.fi/sv/laki/alkup/2015/20150156). 
registrada como en Italia o Austria, por ejemplo ${ }^{22}$. En estos países en lugar de crear una institución completamente nueva, simplemente se decidió qué derechos no iban a tener que sí tenían las parejas casadas. Sólo pueden registrarse las parejas del mismo sexo, ya que las de sexo diferente pueden optar por casarse o simplemente cohabitar. El registro de la unión produce efectos equivalentes al matrimonio en casi todos los ámbitos ${ }^{23}$. En estos casos, ¿se les aplicará a las parejas registradas en estos Estados, en los que se las asimila al matrimonio, el Reglamento $1104 / 2016$ o el 1103/2016?24.

La elección de uno u otro Reglamento no es una cuestión baladí, habida cuenta de las notables diferencias entre uno y otro, sobre todo por lo que respecta a la ley aplicable. Así, el Reglamento 1103/2016 sobre régimen económico matrimonial, establece en su artículo 26.1 una serie de puntos de conexión en cascada para determinar la ley aplicable en defecto de un acuerdo de elección por las partes. A saber: a) la ley del Estado de la primera residencia habitual común de los cónyuges tras la celebración del matrimonio, o, en su defecto, b) de la nacionalidad común de los cónyuges en el momento de la celebración del matrimonio, o, en su defecto, c) con la que ambos cónyuges tengan la conexión más estrecha en el momento de la celebración del matrimonio, teniendo en cuenta todas las circunstancias. En cambio, el Reglamento 1104/2016, también en su artículo 26, establece como única posibilidad la aplicación de la ley del Estado donde se ha creado la unión. Lo que resulta extremadamente relevante en el ámbito de las uniones del mismo sexo. En relación a estas parejas, tanto la conexión nacionalidad como la residencia habitual podrían suponer la aplicación de leyes que desconozcan la institución "pareja registrada", teniendo en cuenta que la ley aplicable tiene carácter universal. No se puede olvidar que la pareja registrada a la que se aplica el Reglamento (UE) 2016/1104 se ha de constituir mediante un acto formal ante autoridad pública, y en muchos ordenamientos jurídicos no se exige ningún período de convivencia previo. Las partes, en consecuencia, han podido constituir su unión en un Estado y tener su residencia habitual en otro, en ese momento o posteriormente. La conexión residencia habitual no garantizaba en todas las ocasiones la aplicación de una ley que, aunque estuviese estrechamente vinculada a la pareja, conociera la institución que habían constituido. De ahí lo acertado del Reglamento de establecer el país de constitución como punto de conexión, porque se asegura que la institución no será desconocida, y aporta a las partes mayor seguridad jurídica.

Si se admite que a una misma unión se le puedan aplicar o no los preceptos contenidos en las normas UE debido a su orientación sexual, dependiendo del Estado miembro donde se encuentren, se rompe la uniformidad pretendida. Desde la perspectiva del DIPr tendría que procurarse la continuidad de las relaciones jurídicas en el espacio. Además, sería preciso evitar que, dentro del propio espacio comunitario, se produzcan alteraciones en el estatuto personal del ciudadano, lo cual, redundaría en perjuicio de la respuesta unitaria de soluciones deseable ${ }^{25}$.

22 Ley 76/2016, italiana de uniones civiles (GU n.118de 21-05-2016); Eingetrangene Partnershaft-Gesetz (EPG), de 30 de diciembre de 2009, en Austria.

23 Vid. SWEDDEN, F. Y EGGERMONT, S., "Same-sex Couples in Central Europe: Hop, Step and Jump", Legal Recognition of Same-Sex Relationships in Europe. National, Cross-border and European Perspectives Intersentia, 2012.

24 MARTINY, D., "Die Kommissionsvorschläge für das internationale Ehegüterrrecht Bowie für das internationale Güterrrecht eingetrangener Partnerschaften”, IPRax, 2011, p.443 y ss.

25 ARTUCH IRIBERRI, E., "La libertad individual y las parejas ante el Derecho internacional privado", REDI, vol. LIV, 2002, pp. 41-65 p. 60. 
Es incuestionable que la solución sería la creación de conceptos autónomos con los que se podría lograr una unificación del Derecho de familia. No obstante, actualmente la UE no tiene competencia para ello $^{26}$. Se ha considerado que el Derecho de familia pertenece al núcleo duro de materias civiles refractarias a toda unificación ${ }^{27}$. Se estima que implicaría la desaparición de los Derechos privados nacionales y la constitución de un nuevo Derecho europeo aplicable a situaciones internas e intracomunitarias, indistintamente. La creación de conceptos autónomos, en consecuencia, es actualmente inviable y la inexistencia de un Derecho de familia material en la UE, suscita una gran inestabilidad en el estatus de las parejas que se desplazan.

Sin embargo, el TJUE ha abierto un interesante camino a través de la espesura de la competencia exclusiva de los Estados en esta materia en el famoso asunto Coman relativo a la libre circulación por el territorio de la UE de un matrimonio del mismo sexo, cuyas tesis principales pueden ser extrapoladas, bajo nuestro punto de vista, a las parejas registradas ${ }^{28}$.

El Alto tribunal ha afirmado que el estado civil de las personas, en el que se incluyen las normas relativas al matrimonio, constituye una materia objeto de competencia exclusiva de los Estados miembros. Éstos pueden libremente admitir o rechazar en sus legislaciones el matrimonio entre personas del mismo sexo. No obstante, al ejercitar dicha competencia no pueden vulnerar las libertades de circulación de los ciudadanos de la UE. Es decir, el TJUE obliga al reconocimiento de ese matrimonio y de ese cónyuge únicamente a efectos de conceder un derecho de residencia derivado a un nacional de un tercer Estado indicando que esto no atenta contra la identidad nacional ni amenaza el orden público del Estado miembro afectado ${ }^{29}$.

El argumento del TJUE puede llevarnos a afirmar que una institución válidamente constituida en un Estado miembro tiene que ser reconocida en otro Estado miembro aun-

26 Sobre la unificación del Derecho de familia comunitario y la competencia o incompetencia de la UE para abordar esta labor vid. ANTOKOLSKAIA, M., "Would the Harmonisation of Family Law Enlarge the Gap between the Law in the Books and the Law in Action?", FamPra., 2002, pp. 261-292; BASEDOW, J., "Codificaction of Private Law in the European Union: the Making of a Hybrid", ERPL, 2001, pp. 35-49; DE GROOT, G. R., "Auf dem Wege su einem europäischen (internationales) Familienrecht", ZEuP, 2001, pp. 617-627.

27 GARCÍA CANTERO, G., “¿Derecho de familia europeo?”, Derecho privado europeo, Madrid, Colex, 2003, pp. 1175-1184, p. 1175; PINTENS, W., "Europeanisation of Family Law", Perspectives for the Unification and Harmonisation of Family Law in Europe, Intersentia, 2003, pp. 3-29, p. 6.

28 STJUE 5 junio 2018, C-673/16, Coman-Hamilton. Aborda el caso de un ciudadano rumano (Coman) que contrajo matrimonio en Bruselas con un nacional norteamericano (Hamilton). El Sr. Hamilton deseaba trasladarse a vivir a Rumanía con su cónyuge, el Sr. Coman, al amparo de la Directiva 2004/38/CE de 29 abril 2004 relativa al derecho de los ciudadanos de la Unión y de los miembros de sus familias a circular y residir libremente en el territorio de los Estados miembros. Las autoridades rumanas denegaron la petición de residencia del Sr. Hamilton en Rumanía porque el Código Civil de dicho país prohíbe los matrimonios entre personas del mismo sexo y no reconoce tales matrimonios en Rumanía aunque se hayan celebrado válidamente en otros países.

29 Para un análisis de esta sentencia véase entre otros, ÁLVAREZ GONZÁLEZ, S., “Matrimonio entre personas del mismo sexo para toda la UE? A propósito de las conclusiones del Abogado General en el Asunto Coman", La Ley Unión Europea, № 56, 2018; REQUENA CASANOVA, M., "Libre circulación de los matrimonios del mismo sexo celebrados en el territorio de la Unión Europea: consecuencias del asunto "Coman y otros", Revista de Derecho Comunitario Europeo, № 23, № 62, 2019; JIMÉNEZ BLANCO, P., “"La movilidad transfronteriza de matrimonios entre personas del mismo sexo: la UE da un paso: Sentencia del Tribunal de Justicia de 5 de junio de 2018, asunto C- 673/18: Coman", La Ley Unión Europea, No 61, 2018; STOPPIONI, E. "Une analyse critique de l'arrêt Coman: déconstruction de la consécration de l'obligation de reconnaissance du droit de séjour du conjoint homosexuel", European Papers, European Forum, 27 de febrero de 2019, pp. 1 y ss; STEHLÍK, V. "The CJEU crossing the Rubicon on the same-sex marriages? Commentary on Coman case", International and Comparative Law Review, vol. 18, nº 2, 2018, pp. 85-99. 
que sea a los solos efectos de garantizar la libre circulación de personas. En el caso que estamos analizando para garantizar la aplicación el Reglamento 1104/2016 a las parejas registradas del mismo sexo. Y aunque esto no suponga la unificación de conceptos ni la injerencia en los Derechos de familia nacionales de cada Estado, sí abre la puerta a tener que reconocer la institución creada, lo que puede generar una cierta homogeneización de conceptos en la UE a través de esta vía indirecta.

\section{NATURALEZA DEL REGISTRO. ESPECIAL REFERENCIAA LA ATOMIZACIÓN DEL SISTEMA ESPAÑOL}

El tercero de los problemas relacionados con el ámbito de aplicación personal del Reglamento (UE) 2016/1104 que hemos considerado imprescindible abordar en este trabajo es el relativo a la naturaleza del registro. No se hace referencia en la norma UE a si ha de ser o no constitutivo, si ha de ser un registro único o pueden convivir varios registros diferentes en un mismo Estado, si hay posibilidad de que sea un registro administrativo o tiene que ser un registro civil, si es necesario que constituya una publicidad fiable frente a terceros o no, los principios y requisitos para la inscripción registral, las autoridades competentes para practicar las inscripciones....

Todas estas cuestiones, que son esenciales para dilucidar la cuestión previa de si una determinada pareja entrará o no dentro del ámbito de aplicación de dicho instrumento jurídico, quedan al arbitrio de cada Estado miembro. La decisión, no obstante, resulta complicada teniendo en cuenta las heterogéneas regulaciones sobre las parejas registradas existentes. Y no nos referimos únicamente a los Estados parte del Reglamento, sino a cualquier país del mundo, en sintonía con la teoría expuesta en el primer epígrafe, relativa a la posibilidad de aplicación del Reglamento a las parejas registradas en cualquier Estado, sea o no parte.

La regulación de las parejas registradas se realiza de una manera desigual existiendo una diversidad notable de soluciones de Derecho material que, desgraciadamente, se acompañan de un limitado número de reglas de Derecho internacional privado ${ }^{30}$. La falta de homogeneidad provoca que sea complicado determinar a priori qué uniones contarán con el aval del Reglamento y cuáles no. Y esta dispersión normativa llega quizás a su punto álgido en el ordenamiento jurídico español, en el que no existe una regulación a nivel estatal de las parejas registradas, que son ignoradas de una manera negligente, bajo nuestro punto de vista. Esta inactividad por parte del legislador estatal se presenta en claro contraste con la intensa actividad desarrollada por el legislador autonómico. Todas las Comunidades Autónomas han elaborado leyes sobre parejas (estables, no casadas, registradas....cada una con su denominación concreta) $)^{31}$.

30 Para un estudio en profundidad de las diferentes regulaciones estatales puede consultarse, RODRÍGUEZ PINEAU, E., "Los efectos patrimoniales de las uniones registradas: algunas consideraciones sobre la propuesta de Reglamento del Consejo", Anuario Español de Derecho Internacional Privado, t. XI, 2011, págs. 937-955.

31 En Cataluña la Ley 10/1998, de 15 de julio, de uniones estables de pareja; en Aragón, la Ley 6/1999, de 26 de marzo, relativa a las parejas estables no casadas; en Navarra, la Ley Foral 6/2000, de 3 de julio, para la igualdad jurídica de las parejas estables; en Baleares, la Ley 18/2001, de 19 de diciembre, sobre normas reguladoras de las parejas estables; en el País Vasco, Ley 2/2003 de 7 de mayo reguladora de las parejas de hecho; en la Comunidad Valenciana, Ley 1/2001, de parejas de hecho; en el Principado de Asturias, Ley 4/2002 de 23 de mayo de Parejas estables; en 
Las legislaciones autonómicas no solo difieren en su nomenclatura, sino también en el contenido. Cada una regula la cuestión de manera unívoca: en unas el registro es constitutivo y, en otras, meramente declarativo. En algunas el registro es obligatorio y en otras no. En todas, eso sí, se trata de registros administrativos que no alteran el estado civil de los convivientes que siguen permaneciendo solteros, divorciados o viudos y con absoluta disponibilidad para contraer matrimonio con otra persona. Tampoco gozan estos registros de dos privilegios esenciales con los que sí cuenta el Registro Civil: la fe pública y la publicidad frente a terceros.

Pero dónde creemos imprescindible incidir es en el hecho de que en España no existe un registro único de parejas, sino tantos como Comunidades Autónomas y no están interconectados, lo que puede derivar en situaciones de multiplicidad registral. ¿Será un obstáculo la falta de un registro único para la aplicación del Reglamento 1104/2016?. Para argumentar sobre una base sólida la respuesta a este interrogante tomaremos como referencia otro supuesto en el que la multiplicidad registral ha causado problemas en la aplicación de otras normas de la UE. En concreto la Directiva 2004/38 relativa al derecho de los ciudadanos de la Unión y de los miembros de sus familias a circular y residir libremente en el territorio de los Estados miembros. En este caso, la norma de transposición de la citada Directiva al ordenamiento jurídico español, el RD 240/2007 en su artículo 2 , establecía entre los requisitos que debía de tener la pareja para incluirla en el régimen comunitario, que se tratara de "un registro que impidiera la posibilidad de dos registros simultáneos en dicho Estado" 32 . Es decir, la norma española solo consideraba pareja susceptible de someterse al régimen comunitario a aquella pareja inscrita en un Estado miembro que tuviera establecido un sistema de registro único. Los diferentes Registros de parejas estables existentes en las Comunidades Autónomas o Ayuntamientos españoles no se consideraban válidos como prueba del vínculo de pareja, ya que no impedían la posibilidad de dos registros simultáneos en España ${ }^{33}$.

El Tribunal Supremo anuló esa expresión al considerar que esa exigencia excedía de los establecido en la Directiva 2004/38 que, para definir a los "miembros de la familia", sólo se refiere a la "pareja con la que el ciudadano de la Unión ha celebrado una unión registrada, con arreglo a la legislación de un Estado miembro", sin más exigencias y por esta razón anuló la referida expresión ${ }^{34}$. Razona el TS que si bien la supresión de este requisito puede derivar en situaciones de multiplicidad registral, ello no obsta para

Andalucía, Ley 5/2002, de 16 de diciembre, de parejas de hecho; en Castilla y León, el Decreto 117/2002, de 24 de octubre, por el que se crea el registro de uniones de hecho de Castilla y León y se regula su funcionamiento; en Extremadura la Ley 5/2003, de 20 de marzo, de parejas de hecho de la Comunidad Autónoma de Extremadura; en la Comunidad de Madrid, la Ley 11/2001, de 19 de diciembre, sobre parejas de hecho; en Canarias, Ley 5/2003, de 6 de marzo, para la regulación de las parejas de hecho en la Comunidad Autónoma de Canarias; en Cantabria la Ley 1/2005, de 16 de mayo, de parejas de hecho de la Comunidad Autónoma de Cantabria. Ley 7/2018, de 3 de julio, de Parejas de Hecho de la Comunidad Autónoma de la Región de Murcia (BORM de 6 de julio de 2018); Decreto 30/2010, de 14 de mayo, por el que se crea el Registro de Parejas de Hecho de La Rioja.

32 RD 240/2007, de 16 de febrero, sobre entrada y permanencia en España de ciudadanos de los Estados miembros de la Unión Europea y otros Estados parte en el Espacio Económico Europeo.

33 Instrucción DGI/SGRJ/03/2007.

34 Sentencia de 1 de junio de 2010, de la Sala Tercera del Tribunal Supremo, por la que se anulan varias expresiones de los artículos 2, 3, 4, 9 y 18 y disposición final tercera del Real Decreto 240/2007, de 16 de febrero, sobre entrada, libre circulación y residencia en España de ciudadanos de los Estados miembros de la U.E. y de otros Estados parte en el Acuerdo sobre el Espacio Económico Europeo (BOE núm. 266, de 3 de noviembre de 2010). 
que las vías de fraude puedan resolverse por otros cauces. Tiene que ser la administración competente y no el ciudadano la que, caso por caso, atienda si existe o no fraude. Por tanto, actualmente, el certificado del registro realizado en una Comunidad Autónoma es totalmente válido a efectos de concesión de la tarjeta de residente comunitario ${ }^{35}$.

Tomando como referencia el razonamiento expresado por el Tribunal Supremo en este asunto, no parece desatinado afirmar que la multiplicidad de registros no es óbice para la aplicación del Reglamento 2016/1104. Tampoco que el registro sea declarativo, ni siquiera que sea un registro administrativo. Según la opinión de RODRÍGUEZ BENOT, con la que coincidimos plenamente, "no se trataría de la lex causae (u ordenamiento aplicable al fondo de los efectos patrimoniales de la unión) sino de la lex registrii (u ordenamiento del Estado de registro de la unión). Por consiguiente, desde una interpretación finalista sería esta Ley la que indicaría si el registro de la unión en cuestión sería constitutivo o declarativo, cabiendo considerar pues que estarían ambas posibilidades admitidas por el Reglamento"36.

Lo único que parece claro, por tanto, es que el registro tiene que existir y ha de ser obligatorio $^{37}$. Es decir, solamente las uniones extramatrimoniales nacidas a partir de legislaciones en las que la inscripción en un registro público es obligatorio, podrán incluirse en el ámbito de aplicación del Reglamento (UE) 2016/1104, mientras que, modalidades de unión estable de pareja, como la catalana, en la que la unión puede derivarse de una convivencia de al menos dos años o de la tenencia de un hijo en común, quedarán fuera de su ámbito de aplicación ${ }^{38}$. O como la asturiana, en la que la existencia de pareja estable o el transcurso del año de convivencia podrán acreditarse a través de cualquier medio de prueba admitido en Derecho, no necesariamente mediante el registro, aunque es una de las formas de prueba (artículo 3.3 de la Ley 4/2002).

\section{CONCLUSIONES}

La diferente o nula regulación de las uniones registradas que realizan los Estados miembros de la UE, unida a la diversidad de reglas de Derecho internacional privado aplicables

35 Instrucción DGI/SGRJ/03/2010 sobre aplicación de la sentencia del TS de 1 de junio de 2010, relativa a la anulación de varios apartados del RD 240/2007, sobre entrada y permanencia en España de ciudadanos de los Estados miembros de la Unión Europea y otros Estados parte en el Espacio Económico Europeo, de 4 de noviembre de 2010.

36 RODRÍGUEZ BENOT, A, "Los efectos patrimoniales de los matrimonios y de las uniones registradas en la Unión...", loc. cit., p. 25.

37 No está totalmente de acuerdo con esta afirmación PÉREZ MILLA, J.J. (“Efectos patrimoniales de las uniones registradas autonómicas y Reglamentos de la unión europea: respondiendo a problemas complejos", Revista de Derecho Civil Aragonés, 2019, pp.129-155, p. 154) que considera que "la inscripción de la pareja en un Registro autonómico es un acto realizado ante la autoridad pública correspondiente y de la que se derivan unos efectos jurídico-patrimoniales "obligatorios" según los distintos Derechos civiles territoriales españoles, cualquiera que sea la Ley autonómica que ampare dicha formalización. Al concurrir estos dos factores, se cumple con el requisito de que el registro de la pareja sea "obligatorio conforme a dicha ley".

38 MARÍN CORSANAU, D., afirma que el Registro de parejas estables creado a través de la ORDRE JUS/44/2017, de 28 de marzo (DOGC de 31 de marzo de 2017), es un registro administrativo, que no tiene ni carácter obligatorio ni constitutivo y al que se accede con carácter voluntario si se cumplen con los requisitos previstos en el libro segundo del Código Civil de Cataluña ("Las "uniones registradas" en España como beneficiarias del derecho de la UE a propósito de la Directiva 2004/38/CE y del Reglamento (UE) 2016/1104”, Cuadernos de Derecho Transnacional, Octubre 2017, Vol. 9, № 2, pp. 419-447, p.424. 
a sus derechos de propiedad, hacían imprescindible la elaboración del Reglamento (UE) 2016/1104. No obstante, su aplicación se ha convertido en un auténtico desafío para las autoridades competentes, al no incluir una definición autónoma de pareja registrada, dejando a la calificación interna de cada Estado esta labor, con la complejidad que esto lleva aparejado $^{39}$. La ausencia de la determinación del país de registro, la naturaleza del mismo, o de una mención expresa a las parejas del mismo sexo, dificulta la consecución del pretendido "marco jurídico claro" y la libre circulación de estas parejas por el territorio de la $\mathrm{UE}^{40}$. Esta disparidad de regulaciones hubiese requerido, a nuestro juicio, la creación de unos estándares mínimos europeos antes de elaborar una norma de estas características.

Por su parte, la singularidades de del sistema español, con la heterogénea regulación autonómica de las uniones registradas, complican aún más su aplicación en nuestro país.

Cada una regula la cuestión de manera diferente: en unas el registro es constitutivo y, en otras, meramente declarativo. En algunas el registro es obligatorio y en otras no. En todas, eso sí, se trata de registros administrativos que no alteran el estado civil de los convivientes, ni dan fe pública, ni publicidad frente a terceros. Y aunque bajo nuestra consideración todas las uniones extramatrimoniales nacidas a partir de legislaciones autonómicas en las que el la inscripción sea obligatoria podrán incluirse en el ámbito de aplicación del Reglamento, no existe unanimidad doctrinal en este sentido. Un escenario que desde luego, en nuestra opinión, tenía que haberse anticipado antes de vincularnos al procedimiento de cooperación reforzada a fin de evitar el caos que se avecina ${ }^{41}$.

\section{BIBLIOGRAFÍA}

Álvarez GonzÁLEZ, S. “¿Matrimonio entre personas del mismo sexo para toda la UE? A propósito de las conclusiones del Abogado General en el Asunto Coman”, La Ley Unión Europea, № 56, 2018.

Andrés SÁEnz De SANTA MaríA, P. "El tiempo de las cooperaciones reforzadas y los acuerdos inter se en la Unión Europea: ¿todos los instrumentos llevan a la integración?”, La Ley: Unión Europea, núm. 10, 2013, pp. 5-28.

Antokolskaia, M. "Would the Harmonisation of Family Law Enlarge the Gap between the Law in the Books and the Law in Action?", FamPra., 2002, pp. 261-292.

ARTUCH IRIBERRI, E. "La libertad individual y las parejas ante el Derecho internacional privado", REDI, vol. LIV, 2002, pp. 41-65.

Basedow, J. "Codificaction of Private Law in the European Union: the Making of a Hybrid", ERPL, 2001, pp. 35-49.

Bauman, Z. Liquid Modernity, Cambridge, Polity Press, 2000.

CAmpuzano DíAz, B. ("La política legislativa de la UE en materia de DIPr. de familia. Una valoración de conjunto", Cuadernos de Derecho Transnacional, 2013, Vol. 5, No 2, pp. 234-264.

39 GRECO, U., "La regulación jurídica de las relaciones patrimoniales de las parejas internacionales en la UE", Revista Peruana de Derecho Internacional, Tomo LXX Enero-Abril 2020, № 164, pp. 159-186.

40 De la misma opinión, RODRÍGUEZ PINEAU, E., "Los efectos patrimoniales de las uniones registradas: algunas consideraciones sobre la propuesta de Reglamento del...", loc. cit., p.944.

41 En la misma línea, PALAO MORENO, G., "La determinación de la ley aplicable en los Reglamentos en materia de régimen económico matrimonial y efectos patrimoniales de las uniones registradas 2016/1103 y 2016/1104", REDI, Vol. 71, enero-junio 2019, pp. 89-117, p. 117. 
De Groot, G. R. "Auf dem Wege su einem europäischen (internationales) Familienrecht”, ZEuP, 2001, pp. 617-627.

García Cantero, G. “¿Derecho de familia europeo?”, Derecho privado europeo, Madrid, Colex, 2003, pp. $1175-1184$.

GonzÁLEz Beilfuss, C. Parejas de hecho y matrimonios del mismo sexo en la UE, Barcelona, Marcial Pons, 2004.

GRECO, U. "La regulación jurídica de las relaciones patrimoniales de las parejas internacionales en la UE", Revista Peruana de Derecho Internacional, Tomo LXX Enero-Abril 2020, ํ 164, pp. 159-186.

JiMÉNEZ BlANCO, P. "La movilidad transfronteriza de matrimonios entre personas del mismo sexo: la UE da un paso: Sentencia del Tribunal de Justicia de 5 de junio de 2018, asunto C- 673/18: Coman", La Ley Unión Europea, № 61, 2018.

Marín Corsanau, D. "Las "uniones registradas" en España como beneficiarias del derecho de la UE a propósito de la Directiva 2004/38/CE y del Reglamento (UE) 2016/1104", Cuadernos de Derecho Transnacional, Octubre 2017, Vol. 9, № 2, pp. 419-447.

Martiny, D. "Die Kommissionsvorschläge für das internationale Ehegüterrrecht Bowie für das internationale Güterrrecht eingetrangener Partnerschaften", IPRax, 2011, p.443 y ss.

Palao Moreno, G. "La determinación de la ley aplicable en los Reglamentos en materia de régimen económico matrimonial y efectos patrimoniales de las uniones registradas 2016/1103 y 2016/1104", REDI, Vol. 71, enero-junio 2019, pp. 89-117.

PÉrez Milla, J. J. "Efectos patrimoniales de las uniones registradas autonómicas y Reglamentos de la unión europea: respondiendo a problemas complejos", Revista de Derecho Civil Aragonés, 2019, pp.129-155.

Pintens, W. "Europeanisation of Family Law", Perspectives for the Unification and Harmonisation of Family Law in Europe, Intersentia, 2003, pp. 3-29.

Pintens, W. "Union européenne et l'émergence d'un droit international de la famille - L'exemple des régimes matrimoniaux et des effets patrimoniaux des partenariats enregistrés", Herausforderungen an Staat und Verfassung. Liber Amicorum für Torsten Stein zum 70. Geburtstag, Nomos, 2015, pp.806-822.

QuinzÁ Redondo, P. "Unificación -fragmentada- del Derecho internacional privado de la Unión Europea en materia de régimen económico matrimonial: el Reglamento 2016/1103", Revista General de Derecho Europeo, núm. 41, 2017, pp. 180-222.

QuiÑones EsCÁMEZ, A. "Nuevos tipos de uniones y nueva regulación de sus efectos", Persona y familia en el nuevo modelo español de Derecho internacional privado, Tirant lo Blanch, Valencia, 2017, pp.169-189.

QuiÑones EsCÁMEZ, A. "Problemas generales de derecho internacional privado en los nuevos reglamentos europeos en materia de regímenes matrimoniales y efectos patrimoniales de las uniones registradas", Cursos de derecho internacional y relaciones internacionales de Vitoria-Gasteiz, $\mathrm{n}^{\circ}$ 1, 2018, pp. 245 -335.

Requena Casanova, M. "Libre circulación de los matrimonios del mismo sexo celebrados en el territorio de la Unión Europea: consecuencias del asunto "Coman y otros", Revista de Derecho Comunitario Europeo, $\mathrm{N}^{\circ} 23, \mathrm{~N}^{\circ} 62,2019$.

Rodríguez Benot, A. "Los efectos patrimoniales de los matrimonios y de las uniones registradas en la Unión Europea", Cuadernos de derecho transnacional, Vol. 11, núm. 1, 2019, pp.8-50.

Rodríguez Pineau, E. "Los efectos patrimoniales de las uniones registradas: algunas consideraciones sobre la propuesta de Reglamento del Consejo", Anuario Español de Derecho Internacional Privado, t. XI, 2011, págs. 937-955.

Sото МоуA, M. "El Reglamento 1104/2016 sobre régimen patrimonial de las parejas registradas: algunas cuestiones controvertidas de su puesta en funcionamiento en el sistema español de DIPr.", REEI, núm. 35, diciembre 2018. 
STEHLík, V. "The CJEU crossing the Rubicon on the same-sex marriages? Commentary on Coman case", International and Comparative Law Review, vol. 18, $\mathrm{n}^{\mathrm{o}}$ 2, 2018, pp. 85-99.

Stoppioni, E. “Une analyse critique de l'arrêt Coman: déconstruction de la consécration de l'obligation de reconnaissance du droit de séjour du conjoint homosexuel", European Papers, European Forum, 27 de febrero de 2019, pp. 1 y ss.

Swedden, F. And Eggermont, S. "Same-sex Couples in Central Europe: Hop, Step and Jump", Legal Recognition of Same-Sex Relationships in Europe. National, Cross-border and European Perspectives Intersentia, 2012. 